\title{
HARMONI ISLAM DAN BUDAYA JAWA DALAM TAFSIR KITAB SUCI AL-QUR'AN BASA JAWI
}

\author{
S. Supriyanto \\ Institut Agama Islam Negeri Surakarta \\ Jl. Pandawa, Pucangan, Kartasura, Sukoharjo, Jawa Tengah, Indonesia \\ E-mail: supriyanto.mud@gmail.com
}

\begin{abstract}
This study aims to describe the harmonic modes between Islam dan Javanese culture in Javanese qur'anic commentary. The object material is Tafsir Al-Qur'an Suci Basa Jawi which studied using Gadamer's hermeneutics. This is the book of tafsir which written based on the idea of Tafsir Anom V. The tafsir then was written, compiled, and publishd by KH. Raden Muhammad Adnan (1889-1969) and his descendants who lived in Keraton Surakarta. The study shows that Tafsir Al-Qur'an Suci Basa Jawi is one of local qur'anic commentaries which strengthen harmonic modes between Islam and Javanese culture. There are three points of Javanese culture in harmony with Islam: the use of respectful language in Javanese, a harmony of Javanese Islamic mysticism and Javanese Islam as a way of wisdom. This is a local qur'anic commentary that harmonize the Javanese local culture with Islam.
\end{abstract}

Keywords:

Qur'anic commentary; Tafsir; Anom; Kiai Adnan; Javanese culture; harmony.

\begin{abstract}
Abstrak
Artikel ini bertujuan mendeskripsikan keselarasan ajaran Islam dan budaya Jawa dalam tafsir Alquran. Objek kajiannya adalah Tafsir Al-Qur'an Suci Basa Jawi. Sebuah karya yang gagasannya berasal dari Tafsir Anom V, lalu ditulis, disusun, dikumpulkan dan dipublikasikan oleh K.H. Raden Muhammad Adnan (1889-1969) dan anakanaknya yang berada di lingkungan Keraton Surakarta. Melalui pendekatan hermeneutik Gadamer, kajian ini menunjukkan bahwa Tafsir Al-Qur'an Suci Basa Jawi merupakan salah satu karya yang memperkuat keselarasan Islam dan budaya Jawa. Harmoni Islam Jawa tampak pada penggunaan bahasa Jawa halus atau hormat, mistisisme Islam Jawa berupa keselarasan lahir-batin dan keharmonisan Islam Jawa sebagai jalan kebijaksanaan. Sebuah karya tafsir lokal di Nusantara yang mampu mengharmoniskan unsur budaya lokal dengan ajaran Islam.
\end{abstract}

Kata Kunci:

Tafsir Alquran; Tafsir Anom; Kiai Adnan; budaya Jawa; harmoni.

DOI: $10.15575 /$ jw.v3i1.2578

Received: June 2018; Accepted: August 2018; Published: August 2018 


\section{A. PENDAHULUAN}

Sepanjang sejarah Islam, terdapat ribuan karya tafsir Alquran yang ditulis oleh para ulama klasik, modern maupun kontemporer dengan menggunakan ragam bahasa, seperti Arab, Persia, Urdu, Melayu, Inggris, dan lainlain. ${ }^{1}$ Hal ini dilakukan untuk memperoleh pemahaman yang memadai tentang Alquran dan mengungkapkan berbagai petunjuk di dalamnya sesuai dengan perubahan ruang dan waktu. $^{2}$ Alquran sebagai kitab petunjuk $(\text { hudan })^{3}$ telah melahirkan aneka pengalaman dan pemahaman dari setiap individu yang berinteraksi dengannya, salah satunya berupa karya tafsir. $^{4}$

Di Indonesia, tafsir Alquran sudah banyak ditulis dan dipublikasikan hingga sekarang. ${ }^{5}$ Sebagai kawasan yang seringkali disebut sebagai pinggiran Islam, bisa dipahami perkembangan tafsir di Indonesia relatif berkembang belakangan dibanding tradisi tafsir di Timur Tengah sebagai pusat keilmuan Islam. ${ }^{6}$ Tradisi tafsir juga tidak lebih dahulu

\footnotetext{
${ }^{1}$ Tentang tafsir, lihat Claude Gilliot, "Exegesis of the Qur'ān: Classical and Medieval," in Encyclopaedia of the Qur'ān, ed. oleh Jane Dammen McAuliffe, Qur'ānic Studies Online (Leiden-Boston-Koln: Brill, 2001), 99124. Lihat juga Rotraud Wielandt, "Exegesis of the Qur'an: Early Modern and Contemporary," in Encyclopaedia of the Qur'an, ed. oleh Jane Dammen McAuliffe (Leiden-Boston-Koln: Brill, 2001), 124-42.

${ }^{2}$ Al-Sayyid Muhammad Rashid Rida, Tafsir AlQur'an Al-Hakim Al-Mashhur Bi'ism Tafsir Al-Mana, vol. Juz 1 (Kairo: Munsha Al-Manar, 1947), 4.

${ }^{3}$ Alquran secara eksplisit meneguhkan fungsinya tersebut, di antaranya terdapat pada QS. Al-Baqarah/2: 2, 185; Ali 'Imran/2: 138; Al-A'raf/7: 52; An-Nahl/16: 64, 89, 102; An-Naml/27: 77; dan Al-Jatsiah/45: 11, 20.

${ }^{4}$ Tafsir salah satunya didefinisikan sebagai penjelas, penyingkapan dan penampakan makna-makna yang dapat dipahami dengan akal. Muhammad Husain AlDhahabi, Tafsîr Wa Al-Mufassirûn, vol. Juz I (Kairo: t.p., 1979), 15. Lihat juga Manna' Khalil' Al-Qattan, Mabahis Fi "Ulum Al-Qur"an (Beirut: Mansyurat alAsr al-Hadis, t.th.), 323.

${ }^{5}$ Howard M. Federspiel, Popular Indonesian Literature of the Qur'an (Ithaca, New York: Cornel Modern Indonesia Project, 1994).

${ }^{6}$ Howard M. Federspiel, "An Introduction to Qur'anic Commentaries in Contemporary Southeast Asia," The Muslim World 81, no. 2 (1991): 149-161, https://doi.org/10.1111/j.1478-1913.1991.tb03519.x.
}

berkembang dibanding keilmuan Islam lainnya, terutama seperti tasawuf dan fikih. ${ }^{7}$ Tafsir di Indonesia bukan hanya ditulis menggunakan bahasa Arab dan Indonesia, tetapi juga dipublikasikan dengan menggunakan ragam bahasa lokal-daerah, seperti Melayu, Jawa, Sunda, Bugis, Aceh dan lainlain. Karenanya, signifikansi tafsir (dan terjemah) Alquran berbahasa lokal terletak pada kekayaan bahasanya sebagai cermin keragaman etnis di Indonesia. ${ }^{8}$

Salah satu karya tafsir yang ditulis dalam bahasa Jawa adalah Tafsir Al-Qur'an Suci Basa Jawi karya Kanjeng Raden Penghulu Tafsir Anom V (1854-1933) dan K.H. Raden Muhammad Adnan (1889-1969) (selanjutnya disebut Tafsir Anom dan Kiai Adnan). Keduanya merupakan ulama di Kraton Surakarta. Tafsir ini pertama kali diterbitkan menggunakan aksara Pegon oleh Perkumpulan Mardikintoko di bawah prakarsa Kiai Adnan pada tahun 1924. Berkat usaha anaknya, Abdul Basit Adnan, naskah tafsir ini lalu dipublikasikan dalam aksara Latin pada tahun 1970-an. ${ }^{9}$

Belum banyak sarjana yang melakukan kajian terhadap Tafsir Al-Qur'an Suci Basa Jawi ini. Beberapa sarjana sudah cukup banyak yang mengkaji budaya Jawa dalam tafsir-tafsir berbahasa Jawa seperti tafsir $A l$ Iklil fi Ma'ani al-Tanzil karya K.H. Misbah Mustafa, Al-Ibriz karya K.H. Bisri Mustafa, Faid al-Rahman karya K.H. Salih Darat, AlHuda karya Bakri Syahid dan lainnya. ${ }^{10}$

${ }^{7}$ Mamat S. Burhanuddin, Hermeneutika Ala Pesantren (Yogyakarta: UII Pres Yogyakarta, 2006), 6.

${ }^{8}$ Jajang A Rohmana, "Memahami Al-Qur'an dengan Kearifan Lokal: Nuansa Budaya Sunda dalam Tafsir Al-Qur'an Berbahasa Sunda," Journal of Qur'an and Hadith Studies 3, no. 1 (2014): 79-99.

${ }^{9}$ Islah Gusmian, "Tafsir Al-Qur'an di Indonesia: Sejarah dan Dinamika," Nun 1, no. 1 (2015): 1-32.

${ }^{10}$ M Muchoyyar HS, "KH. Muhammad Shalih AlSamarani: Studi Tafsir Faid Al-Rahman Fi Tarjamah Tafsir Kalam Malik Al-Dayyan" (Disertasi: UIN Sunan Kalijaga Yogyakarta, 2000). Lihat juga Ahmad Baidowi, "Aspek Lokalitas Tafsir Al-Iklīl Fī Ma'ānī Al-Tanzīl Karya KH Mishbah Musthafa," Nun 1, no. 1 (2015): 33-62. Lihat juga Islah Gusmian, "Tafsir AlQur'an Bahasa Jawa: Peneguhan Identitas, Ideologi dan 
Tetapi, belum banyak yang mengkaji aspek budaya Jawa dalam Tafsir Al-Qur'an Suci Basa Jawi ini.

Junaidi misalnya, keduanya mengkaji karya tersebut dilihat dari perspektif berbeda. Ia mengkajinya tidak saja dari sisi politik ortodoksi Islam di Keraton Surakarta, tetapi juga dilihat dari kepengarangannya yang berasal dari naskah Tafsir Alquran al-Adzim karya Raden Penghulu Tafsir Anom V, ayah Kiai Adnan. Menurutnya, Tafsir Al-Qur'an Suci Basa Jawi memiliki kandungan yang sama dengan naskah Tafsir Alquran al-Adzim yang disusun sebelumnya dalam aksara pegon secara terpisah-pisah untuk setiap juz. Tampaknya ide dasar penulisan kedua tafsir tersebut ada pada Tafsir Anom V, sedangkan Kiai Adnan dan anak-anaknya yang lain menuliskan dan mengumpulkannya hingga menjadi satu tafsir utuh, yakni Tafsir AlQur'an Suci Basa Jawi. Karenanya, Kiai Adnan bukanlah pengarang tafsir tersebut, ia sekedar menghimpun dari tulisan-tulisan yang berserakan sebelumnya. ${ }^{11}$ Temuan Junaidi berbeda dengan pendapat Gusmian yang menganggap tafsir tersebut merupakan karya Kiai Adnan. ${ }^{12}$

Politik Perlawanan," Suhuf 9, no. 1 (November 2016): 141-68, https://doi.org/10.22548/shf.v9i1.116. lihat juga M Maslukhin, "Kosmologi Budaya Jawa dalam Tafsîr al-Ibrîz Karya KH. Bisri Musthofa," Mutawatir $\begin{array}{lllll}\text { 5, no. } & 1 & \text { (2015): }\end{array}$ https://doi.org/10.15642/mutawatir.2015.5.1.74-94. lihat juga Novita Siswayanti, "Javanese Ethical Values in Tafsir Al-Huda," Analisa 20, no. 2 (2013): 207-20, https://doi.org/10.18784/analisa.v20i2.177. lihat juga Ridhoul Wahidi, "Hierarchical Language in the Interpretation of Al-Ibrīz Li Ma'rifah Tafsīr Al-Qur'ān Al-'Āzīz by K.H. Bisri Musthofa," Suhuf 8, no. 1 (2015): 141-160. Lihat juga Supriyanto Supriyanto, “Al-Qur'an Dalam Ruang Keagamaan Islam Jawa: Respon Pemikiran Keagamaan Misbah Mustafa dalam Tafsir al-Iklīl fī Ma'āni al-Tanzīl,’ Jurnal Theologia 28, $\begin{array}{llll}\text { no. } & 1 & \text { (2017): } & \text { 29-54, }\end{array}$ https://doi.org/10.21580/teo.2017.28.1.1294.

${ }^{11}$ Akhmad Arif Junaidi, "Penafsiran Al-Qur'an Penghulu Kraton Surakarta: Interteks Dan Ortodoksi" (Pascasarjana IAIN Walisongo, 2012), 155-157.

${ }^{12}$ Islah Gusmian, "K.H. Raden Muhammad Adnan (1889-1969 M): Ulama dan Pejuang di Bidang Pendidikan, Politik, dan Agama dari Kauman
Kajian ini membahas aspek harmoni budaya Jawa dalam Tafsir Al-Qur'an Suci Basa Jawi tersebut. Sebuah keselarasan yang mencerminkan proses akulturasi berupa penyesuaian diri yang sesuai dengan hakikat kebudayaannya. Proses ini mengarah pada keserasian sosial (social harmony) yang bersifat wajar dan manusiawi. ${ }^{13}$ Tafsir ini mencerminkan apa yang disebut Gadamer sebagai hasil penggabungan horison atau cakrawala dalam teks dan pembacanya. Pengarang Tafsir Al-Qur'an Suci Basa Jawi berhasil menyadari kedua horison itu ketika menafsirkan teks Alquran ke dalam bahasa Jawa. ${ }^{14}$ Isu harmoni budaya lokal ini sangat signifikan terkait peran budaya lokal sebagai bentuk kearifan dalam kehidupan masyarakat di Indonesia. Budaya lokal, termasuk salah satunya budaya Jawa, memiliki posisi penting dalam percaturan kehidupan global. Budaya lokal dalam tafsir Alquran diyakini mampu memberikan suara alternatif Islam dalam memandang kehidupan yang toleran dan akomodatif terhadap perbedaan. ${ }^{15}$

\section{B. HASIL DAN PEMBAHASAN \\ 1. Tafsir Anom dan Kiai Adnan}

Sebagaimana sudah dijelaskan bahwa Tafsir Al-Qur'an Suci Basa Jawi tidak bisa dilepaskan dari dua tokoh utama, yakni Tafsir Anom V sebagai pemilik gagasan dan Kiai Adnan sebagai pengumpul dan pengembang gagasan hingga berwujud publikasi tafsir. Karenanya, bagian ini akan menjelaskan tentang sekilas biografi keduanya agar posisi tafsir tersebut bisa dipahami dengan lebih baik.

Raden Penghulu Tafsir Anom V merupakan penghulu ageng ke-18 dalam dinasti

Surakarta," Jurnal Lektur Keagamaan 15, no. 1 (2018): 207-32, https://doi.org/10.31291/jlk.v15i1.521.

${ }^{13}$ Koentjaraningrat, Pengantar Ilmu Antropologi (Jakarta: Rineka Cipta, 1990), 248.

${ }^{14}$ Hans-Georg Gadamer, Truth and Method (London \& New York: Continuum, 2004), 310.

${ }^{15}$ Imam Muhsin, Penafsiran Al-Qur'an Dan Budaya Lokal: Studi Nilai-Nilai Budaya Jawa Dalam Tafsir AlHuda Karya Bakri Syahid (Jakarta: Badan Litbang dan Diklat Kementerian Agama RI, 2010), 21-22. 
Kartasura. Nama Tafsir Anom diambil dari bahasa Arab Tabsyir Anam berarti pembawa kabar gembira. Lidah orang Jawa menyebutnya Tafsir Anom. ${ }^{16}$ Nama aslinya Raden Muhammad Qamar. Ia lahir pada tahun 1854 di lingkungan pengulon, Surakarta Hadiningrat dan merupakan anak keenam dari Raden Penghulu Tafsir Anom IV. Ia menghabiskan masa kecilnya dengan belajar mengaji Alquran pada sang ayah dan Kiai Mukmin di Kampung Gajahan. ${ }^{17}$

Pada usia 18 tahun, Penghulu Tafsir Anom belajar mengaji di Pesantren Tegalsari Ponorogo lalu ke Pesantren Banjarsari Madiun dan Pesantren Kebonsari Madiun. Pada usia 21 tahun, setelah selesai belajar di pesantren, ia lalu pulang ke Kampung Pengulon. Tetapi, is kemudian kembali belajar memperdalam ilmuilmu keislaman di Pesantren Darat yang diasuh oleh KH. Muhammad Salih Darat hingga berusia 23 tahun. ${ }^{18}$

Pada usia 25 tahun, ia diangkat sebagai pegawai raja (abdi dalem) yang ditugaskan di Jatinom, Klaten, wilayah perdikan yang berada di bawah kekuasaan Kraton Surakarta. Ia lalu diangkat sebagai khatib dan mendapat gelar Khatib Barum. Pada saat menjadi khatib, dia tetap diminta membacakan kitab-kitab keislaman di hadapan raja. Pada tahun1811, ia kemudian menikah dengan anak perempuan dari Mas Ngabehi Praja Marnala. ${ }^{19}$

Pada 1815, ketika umurnya menginjak 30 tahun, Sri Susuhunan Pakubuwana IX mengangkatnya sebagai penghulu ageng kraton menggantikan ayahnya yang meninggal beberapa waktu sebelumnya. Sebagai penghulu ageng yang membawahi semua penghulu di tingkat kabupaten, Raden Penghulu Tafsir Anom adalah penasehat raja di bidang keagamaan yang membuatnya memiliki

\footnotetext{
${ }^{16}$ Ma'mun Pusponegoro, Kauman: Religi, Seni, Dan Tradisi (Surakarta: Paguyuban Kampung Wisata Batik, 2007), 35.

${ }^{17}$ Junaidi, "Penafsiran Al-Qur'an Penghulu Kraton Surakarta: Interteks dan Ortodoksi."

${ }^{18}$ Ghazali Munir, Warisan Intelektual Islam Jawa (Semarang: Wali Songo Press, 2008), 57.

${ }^{19}$ Junaidi, "Penafsiran Al-Qur'an Penghulu Kraton Surakarta: Interteks dan Ortodoksi."
}

hubungan yang sangat dekat dengan keluarga istana. Penghulu memerankan fungsi dan tugas sebagai kepanjangan tangan raja yang berkaitan dengan syariat Islam. ${ }^{20}$ Keberadaannya sudah ada sejak pada masa keraton Kartasura. Dia mengabdi sebagai penghulu ageng selama 49 tahun. Kesehariannya seringkali memakai jubah dan sorban. Ketika pengabdiannya telah mencapai 20 tahun, dia mendapatkan berbagai penghargaan dan gelar Kanjeng dan Pangeran Sentara. Ia meninggal pada 21 September 1933 dan dimakamkan di kompleks pemakaman raja-raja Mataram di Imogiri. ${ }^{21}$ Salah satu anak Tafsir Anom V ini adalah Kiai Adnan, salah satu tokoh penting gerakan sosial, politik dan keagamaan di Surakarta pada masa revolusi fisik. Kiai Adnan merupakan anak ketiga Tafsir Anom dari sembilan saudara kandung, meskipun beberapa catatan silsilah keluarganya juga ada yang menyebutnya sebagai anak keempat. ${ }^{22}$

Kiai Adnan lahir pada tanggal 16 Mei 1889 di kompleks pangulon Kauman, Keraton Surakarta, Jawa Tengah. ${ }^{23}$ Ia tinggal di rumah tradisional Jawa berbentuk joglo serta berpendapa besar, sebuah protipe rumah bagi bangsawan. $^{24}$ Nama kecilnya adalah Muhammad Shauman. Kakeknya, Penghulu Tafsir Anom IV, menjabat penghulu pada masa pemerintahan Sri Susuhunan Paku Buwana VII-IX. Dalam silsilah keluarga disebutkan bahwa silsilahnya sampai pada Sultan Syah Alam Akbar III atau R.

\footnotetext{
${ }^{20}$ Tentang penghulu, lihat Muhamad Hisyam, Caught between Three Fires: The Javanese Pangulu under The Dutch Colonial Administration 1882-1942 (Jakarta: INIS, 2001). Lihat juga Ibnu Qoyim Ismail, Kiai Penghulu Jawa, Peranannya pada Masa Kolonial (Jakarta: Gema Insani Press, 1997).

${ }^{21}$ Junaidi, "Penafsiran Al-Qur'an Penghulu Kraton Surakarta: Interteks dan Ortodoksi.”132-133.

${ }^{22}$ Hakim Adnan, Masjid Tegal Sari Sala Genap 65 Tahun (Solo: Asya Grafika, 1999), 20.

${ }^{23}$ Gusmian, "K.H. Raden Muhammad Adnan (18891969 M): Ulama dan Pejuang di Bidang Pendidikan, Politik, dan Agama dari Kauman Surakarta.”

${ }^{24}$ Koentjaraningrat, Manusia Dan Kebudayaan Di Indonesia (Jakarta: Djambatan, 2004), 334.
} 
Trenggono, Sultan Demak terakhir. ${ }^{25}$ Kiai Adnan merupakan keturunan penghulu secara turun-temurun. Ini berbeda dengan Tafsir Anom VI yang ketika meninggal tahun 1956 tidak digantikan oleh keturunan pengulon, tetapi pihak Kraton mengangkat pejabat senior di bidang agama Islam (Juru Suronoto/Mutihan) yaitu R.T. Hadipaningrat alias Abdul Mukti. ${ }^{26}$

Pada masa kecil hingga remaja, Kiai Adnan hidup di tengah masyarakat yang masih dipengaruhi oleh budaya feodal. Stratifikasi masyarakat Jawa tampak pada pembagian kelas sosial para raja (monarkhi), kepala daerah (provinsi), kepala desa, dan masyarakat desa. $^{27}$ Dibanding ayahnya, Penghulu Tafsir Anom V yang sering memakai jubah dan sorban, Kiai Adnan kerap memakai batik, berjas beskap hitam berenda-renda dan di punggungnya diselipkan keris sebagai kelengkapan busana tradisional Jawa. Tutup kepalanya bercorak khusus, kombinasi model udheng Jawa dan sorban yang berwarna putih. Pakaian model ini dipakai dalam tugas dinas ke kantor Yogaswara (Departemen Urusan Agama Kraton), atau menghadap Sri Susuhunan ke Kraton. ${ }^{28}$

Kiai Adnan pertama kali belajar mengaji pada ayahnya sendiri. Pengetahuan membaca dan menulis Jawanya diperoleh di sekolah partikelir di Solo. Sedangkan pengetahuan baca tulis latin dan pengetahuan umum lainnya diperoleh dengan mengundang guru ke rumahnya. $^{29}$ Pada waktu itu belum banyak sekolah yang didirikan. Sekolah Rakyat seperti

\footnotetext{
${ }^{25}$ Abdul Latif Adnan, Silsilah Keluarga Kanjeng Raden Pengulu Tafsir Anom V (Jakarta: t.p., 2008), 9.

${ }^{26}$ Abdul Basit Adnan, Sejarah Masjid Agung Dan Gamelan Sekaten Di Surakarta (Surakarta: Yayasan Mardikintoko, t.th.), 51.

${ }^{27}$ Zaini Muchtarom, Islam Di Jawa Dalam Perspektif Santri Dan Abangan (Jakarta: Salemba Diniyah, 2002), 6.

${ }^{28}$ Abdul Basit Adnan and Abdul Hayi Adnan, "Prof. K.H.R Muhammad Adnan Dan Pemikirannya Dalam Islam," dalam Lima Tokoh Pengembangan IAIN Sunan Kalijaga Yogyakarta, ed. Moh. Damami (Yogyakarta: Pusat Penelitian IAIN Sunan Kalijaga, 1998), 4.

${ }^{29}$ Adnan dan Adnan, "Prof. K.H.R Muhammad Adnan Dan Pemikirannya Dalam Islam”.
}

Volksscool (Sekolah Desa) maupun HIS (Hollands Inlandse School) masih sangat sedikit jumlahnya. ${ }^{30}$ Kiai Adnan sempat mengenyam pendidikan di Sekolah Rakyat dan Sekolah Manbaul Ulum yang didirikan ayahnya. ${ }^{31}$ Ia lulus dari Madrasah Manbaul Ulum pada usia tujuh belas tahun dan memperoleh Syahadah Islamiyyah (ijazah) peringkat pertama pada 21 April $1906 .{ }^{32}$ Ia juga sempat belajar Islam di beberapa pesantren di Jawa Tengah dan Jawa Timur, antara lain Pesantren Mojosari Nganjuk, Pesantren Mangunsari, Pesanten Tremas Pacitan dan Pesantren Jamsaren. ${ }^{33}$

Setelah selesai belajar di pesantren, pada tahun 1908 Kiai Adnan kemudian pergi ke Mekah untuk memperdalam Islam selama delapan tahun (1908-1916). Ia berguru pada Syekh Mahfuz Al-Tarmasi (1868-1919), ulama asal Tremas, Pacitan; Syekh Ahmad Shata' dan Syekh Ahmad Khatib AlMinangkabawi. ${ }^{34}$ Setelah kembali ke tanah air tahun 1916, ia lalu menikah dengan Siti Maimunah (w. 1943), putri seorang saudagar yang dermawan, Haji Ahmad Shofawi. Atas bantuan mertuanya tersebut, tahun 1928 didirikan Masjid Tegalsari sebagai cikal bakal Pondok Pesantren Ta'mirul Islam, Surakarta. Ia kemudian tinggal di Jalan Bumi 9, Kampung Tegalsari. Dari perkawinannya

\footnotetext{
${ }^{30}$ Volksscool merupakan usaha pendidikan terbesar yang didirikan Belanda untuk memberi kesempatan kepada rakyat belajar membaca, menulis dan berhitung. Sedangkan HIS merupakan lembaga utama untuk memperoleh pendidikan Barat, khususnya mempelajari bahasa Belanda sebagai kunci untuk pendidikan lanjut dan syarat untuk memperoleh pekerjaan. Nasution, Sejarah Pendidikan Indonesia (Jakarta: Bumi Aksara, 1995), 88-89.

${ }^{31}$ Pusponegoro, Kauman: Religi, Seni, Dan Tradisi, 46-47.

${ }^{32}$ Muhammad Adnan, Mutiara Hikmah (Solo: Perkumpulan Mardikintoko, 1996), 6. Lihat juga Adnan, Masjid Tegal Sari Sala Genap 65 Tahun, 20.

${ }^{33}$ Norma Setyowati and Danur Hadi Prasojo, Ritual Dalam Proses Pembangunan Masjid, Studi Kasus Pembangunan Masjid Tegalsari Surakarta (Surakarta: t.p., 2008), 13.

${ }^{34}$ Gusmian, "K.H. Raden Muhammad Adnan (18891969 M): Ulama dan Pejuang di Bidang Pendidikan, Politik, dan Agama dari Kauman Surakarta,” 213.
} 
tersebut, Kiai Adnan dianugerahi 15 orang anak. Tetapi, putra-puterinya yang pertama sampai keenam meninggal pada usia balita. ${ }^{35}$ Pada 21 April 1930, Kiai Adnan dianugerahi putra ketujuh bernama Abdul Hayiy lalu lahirlah putra-putrinya yang lain. Di antara putra-putrinya dari hasil pernikahannya dengan Siti Maimunah adalah: Abdul Hayyi (1930-2003), Abdullah Adnan (1931-1999), Abdul Basit Adnan (1933-2003), Muhtaromah (1936-2002), Abdul Hakim (1937-1996), Abdul Nur (lahir 1938), Abdul Hadi (lahir 1940) dan Abdul Latif (lahir 1943). Setelah Maimunah meninggal, Kiai Adnan lalu menikah lagi dengan Salamah pada bulan Desember 1943. ${ }^{36}$ Kiai Adnan meninggal pada 24 Juni 1964 dan dimakamkan di makam Barisan Kiai, Pajang, Surakarta.

\section{Sistematika Tafsir Al-Qur'an Suci Basa Jawi}

Di kalangan masyarakat Jawa, terutama daerah sekitar Keraton Solo dan Yogyakarta, Tafsir Al-Qur'an Suci Basa Jawi memiliki tempat tersendiri. Karya ini tidak bisa dilepaskan dari naskah Tafsir Alquran alAdzim karya Tafsir Anom V, ayah Kiai Adnan, yang diterbitkan oleh al-Maktabah anNabhaniyah, Surabaya. Tafsir yang berjumlah sekitar tiga jilid ini memiliki kandungan yang sama dengan naskah Tafsir Alquran al-Adzim yang disusun lebih dulu dalam aksara pegon secara terpisah-pisah untuk setiap juz. Tampaknya ide dasar penulisan kedua tafsir tersebut ada pada Tafsir Anom V, sedangkan Kiai Adnan dan anak-anak lainnya yang mengumpulkan, membukukan dan mencetaknya dalam aksara latin berupa satu tafsir utuh, yakni Tafsir Al-Qur'an Suci Basa Jawi. ${ }^{37}$ Karenanya, tafsir tersebut tidak bisa dilepaskan dari sosok ayah dan anak tersebut,

\footnotetext{
24.

${ }^{35}$ Adnan, Masjid Tegal Sari Sala Genap 65 Tahun,

${ }^{36}$ Adnan, Silsilah Keluarga Kanjeng Raden Pengulu Tafsir Anom V, 40.

${ }^{37}$ Junaidi, "Penafsiran Al-Qur'an Penghulu Kraton Surakarta: Interteks dan Ortodoksi,” 155-157
}

yakni Tafsir Anom V, Kiai Adnan dan anakanak lainnya.

Cetakan pertama Tafsir Al-Qur'an Suci Basa Jawi dicetak oleh Perkumpulan Mardikinto tahun 1924. Lalu tahun 1953, Kiai Adnan diyakini menulis kembali karya tersebut. Berkat usaha anak Kiai Adnan, Abdul Basit Adnan, tafsir ini dikumpulkan dan dicetak sekitar tahun 1970-an dan diterbitkan oleh PT. Al-Ma'arif, Bandung dengan hanya mencantumkan nama Kiai Adnan sebagai pengarang. ${ }^{38}$ Sejak diterbitkan tahun 1970-an itulah Tafsir Al-Qur'an Suci Basa Jawi menjadi lebi dikenal sebagai karangan Kiai Adnan.

Terdapat beberapa langkah yang ditempuh dalam sistematika Tafsir Al-Qur'an Suci Basa Jawi. Pertama, sebagaimana tafsir lainnya, tafsir ini didahului dengan penjelasan tentang tempat turunnya surat dan jumlah ayat secara singkat. Tentang surah Al-Fatihah, misalnya, dijelaskan bahwa "Tinurunake ana ing Mekkah, cacahe ayat: 7. Tumurun sawuse surat al-Muddatstsir" (Diturunkan di Mekah, jumlah ayatnya tujuh. Diturunkan setelah surah Al-Muddatstsir). Begitu pula keterangan singkat tentang surah Al-Baqarah: "Tinurunake ana ing Madinah, cacahe ayat 286, kajaba ayat 281 ana ing Mina ing dalem Haji Wada" (Diturunkan di Madinah, jumlah ayatnya 286 , kecuali ayat 281 , diturunkan di Mina pada saat haji Wada').

Kedua, selain keterangan singkat tentang surah, penulis memberi penjelasan tambahan tentang maksud nama surah dalam catatan kaki. Misalnya, nama surah Al-Baqarah, penulis memberikan penjelasan: "Surat $=w a$ tes, Baqarah=sapi. Surat iku nyritakake sapi kang dipragad kanggo sarana nguripake wong mati". ${ }^{39}$ (Surat=wates, Baqarah=sapi. Surah tersebut menceritakan tentang sapi yang disembelih sebagai sarana untuk menghidupkan orang mati). Dengan memberikan

\footnotetext{
${ }^{38}$ Gusmian, "K.H. Raden Muhammad Adnan (18891969 M): Ulama dan Pejuang di Bidang Pendidikan, Politik, dan Agama dari Kauman Surakarta," 229.

${ }^{39}$ R. Muhammad Adnan, Tafsir Al-Qur'an Suci Basa Jawi (Bandung: Al-Ma'arif, t.th.), 14.
} 
keterangan tersebut, pembaca Tafsir AlQur'an Suci Basa Jawi ini dengan mudah bisa memperoleh informasi tentang surah yang dibaca, baik alasan penamaannya atau kandungannya.

Ketiga, tafsir ini, sebagaimana umumnya tafsir berbahasa lokal lainnya, juga menggunakan terjemah. Terjemah yang digunakan cenderung pada apa yang disebut al-Dhahabi sebagai terjemah tafsiriyah. ${ }^{40}$ Terjemah tafsiriyah atau maknawiyah merupakan jenis terjemah yang tidak terlalu terikat pada uruturutan redaksi bahasa sumber (source language) dan tidak menggunakan makna harfiyah (literal), tetapi, ia memberikan terjemah secara yang bebas. Terjemahan ini mengutamakan ketepatan makna dan maksud secara sempurna dengan konsekuensi terjadi perubahan urut-urutan kata atau susunan kalimat. ${ }^{41}$ Misalnya, ayat 'wa ja' a rabbuka wa al-malak saffan saffan” (QS. Al-Zumar), yang diterjemah secara tafsiriyah menjadi: "Parentahe Pangeranira kelaksanan lan malaikat jejer-jejer" ${ }^{, 2}$ (perintah Tuhanmu telah terlaksana, dan para Malaikat saling berbaris). Penerjemahan kata ja'a rabbuk dengan "parentahe Pangeranira kelaksanan" (perintah Tuhanmu telah terlaksana) sudah tentu merupakan bentuk terjemah tafsiriyah, karena kata ja'a, makna leksikalnya adalah "datang." Tetapi pengarang memberikan terjemah tafsiriyah menjadi "perintah telah terlaksana."

Contoh terjemah tafsiriyah juga tampak pada ayat yamhaqullah al-riba wa yurbi alsadaqat (QS. Al-Baqarah/2: 276). Pengarang menerjemahkannya dengan: "Allah nyirnakake berkahing riba lan nikelake berkahing sadakah". (Allah melenyapkan berkah dari riba dan melipatgandakan berkah dari sedekah).

Terjemah kalimat "yamhaqullah al-riba" dengan "Allah nyirnakake berkahe riba" (Allah melenyapkan keberkahan dari harta riba) merupakan terjemah bebas dan tidak

\footnotetext{
${ }^{40}$ Al-Dhahabi, Tafsîr wa al-Mufassirûn, 21-22.

${ }^{41}$ Ismail Lubis, Falsifikasi Terjemahan Al-Qur'an (Yogyakarta: Tiara Wacana, 2001), 61-62.

${ }^{42}$ Adnan, Tafsir Al-Qur'an Suci Basa Jawi, 1056.
}

terikat pada bahasa sumber yang hanya menunjuk pada kalimat "Allah akan melenyapkan riba," tanpa ada kata "keberkahan" di sana. Tambahan kata "berkahe" merupakan penafsiran pengarang yang menyimpang dari redaksi bahasa sumber. Begitu pula terjemah kalimat "wayurbi al-sadaqat" dengan "lan nikelake berkahing sadakah" (melipatgandakan berkah dari sedekah) yang menambah kata "berkahing."

Keempat, ayat-ayat Alquran yang diterjemah ke bahasa Jawa secara tafsiriyah tersebut lalu juga diberi penafsiran dalam bentuk catatan kaki (footnote). Misalnya, penafsiran di catatan kaki ketika menafsirkan QS. Al-Baqarah/2: "lilladhin yu'lun min nisa'him tarabbus arba'ah ashhur fa in fa'u fainnallah ghafur rahim". Pengarang menerjemahkannya dengan:

Wong kang pada supata (ila'), ninggal wadone iku, kena nyrantekake (suwesuwene) patang sasi, sawesi iku menawa dhewekw padha gelem balen satemene Allah iku Maha Pangapura sarta Maha Asih

Artinya: "orang-orang yang bersumpah (ila'), meninggalkan istrinya, bisa menunggu (lama-lamanya) empat bulan, setelah itu jika keduanya mau bersatu lagi sesungguhnya Allah maha pengampun dan maha pengasih.

Pengarang memberikan penafsiran dengan memberikan catatan kaki pada kata supata (ila') sebagai berikut: 'Ila' tegese supata ora cumbana karo rabine, lawase luwih 4 sasi utawa tanpa wates" (Ila' yaitu bersumpah untuk tidak menggauli isterinya. Lamanya lebih dari 4 bulan atau tak terbatas). Penjelasan tersebut menunjukkan penafsiran pengarang Tafsir Al-Qur'an Suci Basa Jawi untuk memperjelas maksud kata ila' tersebut. Pengarang menggunakan catatan kaki sebagai sebuah cara untuk memberikan penafsirannya itu.

Begitu pula penggunaan catatan kaki sebagai bentuk penafsiran dilakukan untuk menjelaskan tentang kembalinya suami dari sumpah ila' masih dalam ayat yang sama: 
Tegege wes ora ono perkarane apa-apa, nanging bojone lanang mau saraneng wes nerjang supata kudu bayar dhendaneng supata kang diarani: Kifarat, yaiku milih salah sijining 4 perkara: a). merdekake kawula kang mukmin tur kang tanpa cacat; b). Sadaqah rejeki marang wong miskin 10, siji-sjine sakmud; c). Nyandangi wong miskin 10. Dene yen ora bisa salahsijining tiga perkara mau kudu pasa 3 dina. ${ }^{43}$

Artinya: maksudnya, sudah tidak ada lagi masalah apa-apa, akan tetapi suaminya tadi sudah menerjang sumpah, maka harus membayar denda dari sumpahnya tadi yang disebut dengan kifarat, yaitu memilih salah satu dari 4 perkara ini: a) memerdekakan budak laki-laki beriman dan juga tidak cacat. b) memberikan sedekah kepada 10 orang miskin, per orang satu mud. c) memberikan pakaian kepada 10 orang miskin. Apabila tidak bisa melaksanakan salah satu dari ke tiga perkara tersebut, harus diganti dengan puasa 3 hari.

Penafsiran melalui catatan kaki juga dilakukan dengan memberi penjelasan pada kisah atau cerita tentang suatu peristiwa yang terkait dengan ayat tertentu dengan tanpa menyebutkan sumber riwayatnya (kemungkinan termasuk jenis cerita isra'iliyat). Contohnya adalah penjelasan tentang QS. Ali 'Imran/3: 44:

Nalikane Siti Maryam dipasrahake dening biyunge marang Baitul Mukkaddas, dicaosake ngladeni ana ing ngarsane Allah, ing kono pangerehing Baitul Mukkaddas 29 wong padha rebutan ngopeni Siti Maryam, mungguh pansaning pasulayan mau disumanggakake ing Allah. Wong samono mau padha golongan gawe tandha yekti sarana padha nyemplungake kalam tembaga ana ing bengawan Ardan. Sing sapa kalame kumambang sarta ora bisa keli yaiku kang diparengake Allah ngopeni Siti Maryam, wusana bareng wong 29 mau bebarengan nyemplungake kalam kang

${ }^{43}$ R. Muhammad Adnan, Tafsir Al-Qur'an Suci, 65. kumambang sarta ora keli mung kalame Zakariya. Dene kalame wong 28 padha. ${ }^{44}$

Selain itu, pengarang juga memberi penjelasan di catatan kaki terhadap makna kata-kata kunci yang terdapat dalam sebuah ayat, meskipun jumlahnya tidak terlalu banyak. Contohnya adalah penafsiran QS. AlBaqarah/2: 104. Setelah diterjemahkan ke dalam bahasa Jawa, terjemah tersebut diberi penjelasan melalui catatan kaki sebagai berikut:

Raa'inaa": tembung Arab tegese "kula mugi panjenengan jangkung, panjenengan serantosaken". Yen tembung ibrani tegesipun gendheng. Ing ngarep para sahabat arep padha matur marang Nabi Muhammad: "raa'inaa" kulo mugi panjenengan serantosaken. Wong Yahudi nuli padha tiru-tiru matur "raa'inaa" nanging karepe ngunek-ngunekke gendheng, netepi tembung Ibrani. Mulane banjur ana dhawuh, para sahabat dilarang matur marang Rasul "raa'inaa". 45

Artinya: "Raa'inna": ungkapan Arab, maksudnya "saya mudah-mudahan engaku kabulkan, engaku sentosakan". Jika bahasa Ibrani kata tersebut maksudnya orang gila. Di depan, para sahabat hendak berkata kepada Nabi "raa'inna" saya semoga engaku sentosakan. Orang yahudi kemudian pada berucap menirukan kata "raa'inna" akan tetapi dengan maksud yang berbeda, yakni mencaci dengan ungkapan orang gila, dengan pemahaman bahasa Ibrani. Kemudian para sahabat diperintahkan untuk tidak menggunakan kata "raa'inna" jika berkata kepada Nabi."

Dilihat dari metode penafsiran yang digunakan melalui penjelasan catatan kaki tersebut, Tafsir Al-Qur'an Suci Basa Jawi cenderung menggunakan metode tafsir bi alra'yi. Sebuah metode penafsiran Alquran dengan menggunakan ijtihad pemikiran yang didasarkan pada penguasaan kaidah bahasa Arab, dalil-dalil sahih dan aturan-aturan yang

\footnotetext{
${ }^{44}$ R. Muhammad Adnan, Tafsir Al-Qur'an Suci, 82.

${ }^{45}$ R. Muhammad Adnan, Tafsir Al-Qur'an Suci, 36.
} 
benar (tafsir bi al-ra'yi al-mahmud). ${ }^{46}$ Pengarang tampak memberikan penekanan tersendiri atas ayat tertentu dan memberikan ulasan lebih lanjut yang terkandung di dalamnya.

Demikian sistematika penafsiran dalam Tafsir Al-Qur'an Suci Basa Jawi yang menunjukkan sejumlah langkah, dari penjelasan ka rakter surah, maksud nama surah, terjemah hingga penjelasan melalui catatan kaki. Tetapi, permasalahan berikutnya, mengapa karya ini diberi judul sebagai tafsir? Meski ia bukan dalam pengertian sistematika tafsir standar, melainkan hanya berupa penjelasan pada catatan kaki, sedang teks intinya sekedar diterjemah secara tafsiriyah? Jawabannya bisa dilihat dari konteks kehadiran Tafsir AlQur'an Suci Basa Jawi yang muncul di tengah-tengah pandangan masyarakat yang masih menganggap haram akan terjemah Alquran ke dalam bahasa selain Arab dibanding tafsir. ${ }^{47}$ Terjemah cenderung dianggap menyamai Alquran dan mustahil bisa menampung bahasa Arab sepenuhnya. Karenanya tak sedikit ulama lebih memilih menamai karyanya sebagai tafsir dibanding terjemah, meski sangat berbeda dengan pola tafsir yang berkembang saat ini. ${ }^{48}$ Selain itu, terbitnya tafsir ini menunjukkan keberanian penulisnya dalam mempublikasikan karyanya dalam bahasa Jawa. Publikasinya juga tampak dilakukan secara bertahap. Awalnya menggunakan aksara pegon, lalu belakangan dicetak dan diterbitkan dalam aksara latin.

Oleh karena itu, kemunculan Tafsir AlQur'an Suci Basa Jawi ini bisa dianggap merupakan sebuah langkah berani dari sosok Tafsir Anom V, Kiai Adnan dan anak-anaknya yang menyusun, mengumpulkan dan mener-

\footnotetext{
${ }^{46}$ Muhammad 'Ali Al-Shabuni, al-Tibyan fî Ulûm al-Qur'an (Jakarta: Dar al-Kutub al-Islamiyah, 2003), 67, 155-157. Lihat juga Thamem Ushama, Methodology of Qur'anic Exegesis (Kuala Lumpur: A. S. Noordeen, 1995), 6

${ }^{47}$ Burhanuddin, Hermeneutika ala Pesantren, 117.

${ }^{48}$ Dadang Darmawan, "Ortodoksi Tafsir: Respons Ulama terhadap Tafsir Tamsjijjatoel-Moeslimien Karya K.H. Ahmad Sanusi” (Sekolah Pascasarjana UIN Syarif Hidayatullah Jakarta, 2009), 166.
}

bitkannya di tengah perdebatan soal terjemah tersebut. Hal ini, tentu bukan hanya bisa dilihat sebagai upaya untuk menyebarkan kandungan isi Alquran, tapi di sisi lain juga bisa dilihat sebagai upaya untuk melestarikan bahasa Jawa yang merupakan bahasa ibu yang diwariskan dan dipelihara di lingkungan Keraton Surakarta, meskipun sosok seperti Tafsir Anom V dan Kiai Adnan misalnya juga menguasai bahasa lainnya seperti Belanda dan Indonesia semasa aktif menjabat sebagai penghulu di masa penjajahan Belanda.

\section{Akulturasi Islam Jawa dalam Tafsir Al- Qur'an Suci Basa Jawi}

Islam dan Jawa merupakan dua entitas yang berbeda. Tetapi, keduanya merupakan dua unsur serasi dan harmonis. Islam bukanlah agama yang antipati terhadap kebudayaan masyarakat, tetapi justru bisa selaras dengan budaya lokal dengan mengadaptasi dan mengelaborasinya dalam kerangka besar budaya Islam. Keserasian Islam dan budaya Jawa bukan saja sekedar terpancar pada keindahan budaya dan jiwa spiritualitas dalam masyarakatnya, tetapi pada kemampuan mengawinkan cerlang budaya lokal Jawa dengan Islam yang membentuk suatu kebaruan dan entitas harmonis yang melahirkan tipe peradaban lebih tinggi dari sebelumnya. Inilah yang menjadi salah satu bentuk genius Islam Nusantara melalui akulturasi budaya. ${ }^{49}$ Salah satu upaya mengawinkan keluhuran ajaran Islam dan budaya lokal Jawa tersebut, misalnya, tampak pada Tafsir Al-Qur'an Suci Basa Jawi. Pengarang menyadari pentingnya kesadaran akan adanya cakrawala dalam teks Alquran berupa nilai keislaman dan horison pembaca berupa kuatnya budaya Jawa yang hidup di tengah-tengah mereka. Kedua cakrawala atau horison itu selalu dihadirkan dalam penafsirannya. Pengarang berusaha menggabungkan dan mengkomunikasikan kedua horison tersebut sehingga bisa menemukan keselarasan. ${ }^{50}$ Sebuah upaya yang

\footnotetext{
${ }^{49}$ Koentjaraningrat, Pengantar Ilmu Antropologi, 248.

${ }^{50}$ Hans-George Gadamer, Truth and Method, 310.
} 
berujung pada adanya keharmonisan antara horison ajaran Islam yang berada pada teks dan horison budaya Jawa yang terdapat pada dunia pembacanya. Hal ini sedikitnya tampak pada tiga aspek, yaitu penggunaan bahasa Jawa halus, keselarasan dalam Sufisme Jawa dan jalan kebijaksanaan dalam Islam Jawa.

\section{Bahasa Jawa Halus (Krama) sebagai Bahasa Tafsir}

Bahasa adalah salah unsur pokok bagi kebudayaan. Ia merupakan unsur pertama dari kebudayaan. $^{51}$ Demikian halnya dengan bahasa Jawa. Ia merupakan salah satu unsur terpenting dalam budaya Jawa. Bahasa Jawa sendiri memiliki beberapa hierarki bahasa, dari tingkat yang paling halus hingga tingkat kasar dan paling kasar. Masyarakat Jawa yang hidup di lingkungan Keraton biasanya menggunakan bahasa Jawa yang paling halus.

Baik Tafsir Anom maupun Kiai Adnan dan anak-anaknya, mereka lahir dan besar di lingkungan Keraton Surakarta. Mereka umumnya sebagai seorang abdi dalem atau pejabat Keraton. Mereka tentu terbiasa menggunakan bahasa Jawa halus atau kromo inggil. Karenanya, bahasa Jawa halus tersebut juga digunakan dalam Tafsir Al-Qur'an Suci Basa Jawi. Memang seperti yang dikemukakan Kiai Adnan dalam kata pengantarnya, tujuan penulisan tafsir ini secara umum adalah untuk menyebarkan ajaran Alquran ke dalam masyarakat pengguna bahasa Jawa. Dengan mengutip QS. An-Nahl/16 ayat 44, ia mengatakan:

Ayat kasebat tunggalipun kathah. Ananging miturut ayat punika sampun cekap terang. Bilih maksudipun Alquran punika katurunaken supados dipun terang-terangaken. Ginanipun Alquran punika dipun terjemahaken kathah sanget. Ummat gampil mengertos tatanan agami mawi wahyu Ilahi, ingkang saget numusi dhumateng sukma manungsa kiyat tinimbang karangan manungsa piyambak. Ingkang nguwatosi manawi boten wonten terjemahan Alquran

\footnotetext{
${ }^{51}$ Kontjaraningrat, Pengantar Antropologi 1 (Jakarta: Rineka Cipta, 2003), 81.
}

saking para ulama, pokok tatanan agama angel dipun mangertosi. Punapa menawa ulama boten kersa jarwakaken (nerjemahaken Alquran), boten kerso maringaken ilmunipun, dipun kuwatosaken golongan ingkang diancam.

Artinya: "Ayat yang semisal di atas banyak disebutkan, akan tetapi menurut ayat itu sudah cukup jelas. Maksud Alquran diturunkan itu agar diperjelas dan dijelaskan. Kegunaan Alquran diterjemahkan banyak sekali. Ummat mudah mengerti ajaran agama dari wahyu Allah lansung, sehingga dapat meresap lansung ke dalam hati manusia dengan kuwat, dari pada karangan manusia sendiri. Yang menjadi permasalahan jika tidak ada terjemahan Alquran dari para ulama, maka pokok tatanan agama sulit di pahami. Jika ulama tidak mau menerjemahkan Alquran dan tidak mau memberikan ilmunya, dihawatirkan termasuk pada golongan yang diancam".

Pengarang Tafsir Al-Qur'an Suci Basa Jawi memandang bahwa Islam adalah agama yang mengajarkan kelembutan. Ketika bertemu dengan kebudayaan Jawa yang menekankan kelembutan, maka terjadi suatu perpaduan yang harmonis. Budaya Jawa mengajarkan keluhuran budi, termasuk ketika berbahasa. Karenanya, ketika seseorang menghadapi cercaan atau celaan dari lawan, maka dihadapinya dengan sikap yang lemah lembut dan bahasa yang halus. Begitu pula ketika menyeru musuh sekali pun sebaiknya dihadapi dengan menggunakan bahasa yang lembut. Hal ini selaras dengan perintah Allah ketika memerintahkan Nabi Musa dan Harun untuk menyeru Fir'aun dengan menggunakan bahasa yang lembut. Hal ini seperti yang diabadikan dalam QS. Thaha/20 ayat 44: "Sira sakloron padha ndawuha Raja Fir'aun kanthi aris (andhap asor), muga-muga dheweke gelem nampa pepeling utawa wedi marang ingsun (Kalian berdua serulah Fir'aun dengan bahasa yang halus, mudah-mudahan mau menerima peringatan atau takut (kepadaku)". ${ }^{5}$

\footnotetext{
${ }^{52}$ R. Muhammad Adnan, Tafsir Al-Qur'an Suci, 541 .
} 
Bukan hanya untuk Fir'aun, Tafsir AlQur'an Suci Basa Jawi menggunakan bahasa Jawa halus untuk semua kalangan. Misalnya untuk manusia yang dimuliakan seperti: para nabi, orang-orang saleh, orang-orang yang berbuat baik, para malaikat dan lain-lain. Begitu pula, orang-orang yang dicela dan dilaknat oleh agama seperti orang-orang yang tak beriman, orang munafik, orang-orang yang berbuat maksiat dan dosa. Hal ini dapat dilihat, misalnya, ketika menjelaskan QS. AlBaqarah/2: 215 dengan sasaran atau objek pembicaraannya (khithâb) adalah Nabi $\mathrm{Mu}-$ hammad:

(Muhammad) para ummatira pada matur ing sira: "kados pundi lampahipun tiyang badhe dermakaken bandhanipun? Sira dawuha: "sadhekaha kang becik kang sira darmakake iku utama, dene kang prayogo didermani iku wong tuane loro lan sanak sedulure, lan para bocah yatim, para wong miskin, wongkang pinuju lelungan (kentekan sangu). Dene sedhekah kebecikan kang padha sira tindakake, Allah ngudaneni marang kebecikan mau. ${ }^{53}$

Artinya: (Muhammad) sekelompok umatmu berkata kepada engkau: "bagaimana caranya orang yang hendak mensedekahkan hartanya? Engkau bersabda: "sedekahlah dengan sesuatu yang baik dari apa yang engaku miliki itu lebih utama, yang terutama kepada kedua orang tuamu dan saudara-saudaramu, kemudian anak yatim, fakir miskin, para musafir (yang kehabisan bekal). Sedekah kebaikan yang telah kalian kerjakan, Allah akan membalas dengan kebaikan yang sama.

Pada ayat lainnya, ketika menafsirkan ayat dengan khithâb-nya adalah orang kafir, maka Tafsir Al-Qur'an Suci Basa Jawi pun tetap menggunakan bahasa Jawa yang sama halusnya. Perhatikan misalnya penjelasan atas QS. Al-Baqarah/2: 170 berikut:

Lan nalikane wong kafir padha didhawuhi: "sira padha ndereka barang kang diturunake dening Allah, "wong-wong mau

${ }^{53}$ R. Muhammad Adnan, Tafsir Al-Qur'an Suci, 85. padha matur: "kita sami nderek punapa ingkang sampun kita panggih, sarta dipun tindakaken dening para tetiyang sepuh sedaya". Dhawuhing Allah: "Apa sanajan wong tuane mau ora mangerti apa-apa sarta padha oleh pituduh. ${ }^{54}$

Artinya: "Tatkala orang-orang kafir diperintah: ikutlah kalian pada apa yang telah diturunkan Allah, " kemudian orang-orang itu berkata:kami semua mengikuti apa yang sudah kami temukan, serta sudah dikerjakan oleh orang-rang tua semuanya". Allah berfirman: "apakah tatkala orang-orang tua tadi tidak mengerti apa-apa akan mendapatkan petunjuk".

Hal ini berbeda dengan tafsir berbahasa Jawa lainnya, seperti tafsir Al-Ibriz karya Kiai Bisri Mustofa yang membedakan penggunaan tingkatan bahasa Jawa sesuai dengan khithâbnya. Jika yang dituju adalah golongan atau pihak-pihak yang dianggap mulia dalam kacamata agama, maka digunakan bahasa Jawa halus. Tetapi, jika khithâb ayat mengacu pada pihak-pihak yang dimurkai, maka digunakan bahasa Jawa yang kasar. Kata qala (berkata) misalnya, jika yang berkata adalah nabi, maka akan diartikan dengan ngendiko (bahasa Jawa halus dari berkata), sementara yang berkata adalah Abu Jahal, maka dimaknai dengan ngucap (bahasa kasar). ${ }^{55}$

Penggunaan bahasa Jawa halus dalam Tafsir Al-Qur'an Suci Basa Jawi tidak terlepas dari lingkungan Keraton Surakarta yang mengajarkan kesantunan kepada siapapun. Tafsir Anom dan Kiai Adnan sebagai penyusun tafsir tersebut meyakini bahasa Jawa halus merupakan bagian dari nilai-nilai luhur dalam budaya Jawa yang sering mengedepankan kesantunan dan kesopanan. Tak peduli meskipun khitâb atau pihak yang disebut atau menjadi pembicaraan adalah orang-orang yang tidak mulia dalam kacamata agama.

\footnotetext{
${ }^{54}$ R. Muhammad Adnan, Tafsir Al-Qur'an Suci, 61.

${ }^{55}$ Tentang tafsir Al-Ibriz Abu Rohkmad, "Telaah Karakteristik Tafsir Arab-Pegon Al-Ibriz," Analisa 18, no. 1 (2011): 27-38, https://doi.org/10.18784/analisa.v18i1.122.
} 


\section{Sufisme Islam Jawa dan Keselarasan Lahir-Batin}

Islam Jawa, seperti dikatakan Woodward, merupakan konstruksi antara kesalehan normatif (syariah), kesalehan mistisme (sufisme) yang dipadukan dengan unsur-unsur Jawa, berupa kebudayaan dan nilai-nilai Jawa. Dalam masyarakat Jawa, hubungan antara sufisme dan kesalehan normatif pada umumnya sering digambarkan dalam istilah perbedaan antara lahir dan batin. Dalam teksteks sufi di Jawa, makna lahiriah Alquran berhubungan dengan pengaturan tingkah laku, sementara makna batinnya berhubungan dengan jalan mistik dan pengetahuan mengenai Allah. ${ }^{56}$

Karenanya, di Jawa, ulama yang menguasai syariat, Alquran, dan hadis, juga sekaligus menjadi sufi. Di sini tidak dipertentangkan antara "ortodoksi" dan "kemurnian," atau antara Islam Jawa dan Timur Tengah. Unsur sufisme dan syariat harus dipahami sebagai aspek-aspek dari sistem keagamaan yang tunggal. ${ }^{57}$ Tafsir Al-Qur'an Suci Basa Jawi yang lahir di lingkungan Keraton Jawa Surakarta sesuai dengan pandangan tersebut. Ini misalnya, tampak pada pandangan pengarang ketika memberikan penjelasan atas QS. Al-Kahfi/18 ayat 60-74 yang menceritakan perjalanan Nabi Musa bersama Nabi Hidir untuk memperoleh ma'rifat. Ia menafsirkan kata 'ilman dengan "ngelmu":

Bareng sak karone wes teko ing watu tilas panggonan leren mau, ketemu karo sawijining kawulaningsun kang wis ingsun paring rahmat (Nabi Hidir) sarta diparingi ngilmu. ${ }^{58}$

Artinya: Tatkala keduanya sudah sampai pada batu yang sudah mereka gunakan beristirahat, bertemulah dengan salah satu

\footnotetext{
${ }^{56}$ Mark Woodward, Islam Jawa: Kesalehan Normatif versus Kebatinan, trans. oleh Hairus Salim "Islam in Java: Normative Piety and Mysticism" (Yogyakarta: LKiS, 1999), 109.

${ }^{57}$ Zamakhsyari Dhofier, Tradisi Pesantren Studi Tentang Pandangan Hidup Kyai (Jakarta: LP3ES, 1994).

${ }^{58}$ R. Muhammad Adnan, Tafsir Al-Qur'an Suci, 514.
}

hamba Allah yang telah Ia berikan rahmat (Nabi Hidir) dan diberikan Ilmu.

Dalam pandangan Islam Jawa, penggunaan istilah "ngelmu" berbeda dengan "ilmu". Istilah "ilmu" biasanya merujuk pada ilmuilmu yang bersifat zhahir seperti syariat serta ilmu-ilmu keislaman yang lain, sementara istilah "ngelmu" seringkali merujuk pada ilmu-ilmu atau pengetahuan yang bersifat batin, seperti ilmu ma'rifat dan hakekat. Nabi Musa banyak bertanya pada Nabi Khidir, karena dia hanya mendasarkan apa yang dilihatnya pada pengetahuan lahiriah saja. Ini berbeda dengan ilmu yang dimiliki oleh Nabi Khidir yang sudah sampai pada tahap ngelmu atau ilmu batin, ma'rifat dan hakekat.

Karenanya, Tafsir Al-Qur'an Suci Basa Jawi memposisikan sufisme bukan sebagai ajaran yang dianggap menyimpang dari Islam seperti yang dituduhkan oleh kalangan puritan. ${ }^{59}$ Justru sufisme diyakini berakar dan bersumber langsung dari Alquran salah satunya seperti ditunjukkan dalam kisah Nabi Musa dan Nabi Khidir tersebut. Mengenai ajaran lahir dan batin atau syariat dan hakekat tampak pula dalam pendapat Kiai Adnan dalam karyanya yang lain:

Tuntunan agama Islam memang benarbenar seperti yang dikatakan tadi: tidak hanya menarangkan kelahiran (duniawiyah) saja dan tidak pula melulu kebatinan (sufisme) semata-mata, tetapi keduaduanya sebagai seorang Muslim wajib menjalankan untuk kesempurnaannya dengan sekuat tenaga... ${ }^{60}$

Oleh karena itu, tasawuf, semua berdasarkan kehalusan ruhani dan tatasusila batin yang sejahtera. Memang dengan adab yang demikian itu, orang paham ilmu kebenaran. Dengan demikian, sah segala perbuatannya. Dengan amal demikian, ia memperoleh hikmat kebijaksanaan, lalu dapat zuhud, berdiri tegak meninggalkan tipuan dunia. Dengan jalan demikian, lalu cinta kepada yang benar (haq) atau yang

\footnotetext{
${ }^{59}$ Deliar Noer, Gerakan Modern Islam di Indonesia, 1900-1942 (Jakarta: LP3ES, 1980).

${ }^{60}$ Muhammad Adnan, Mutiara Hikmah, 66.
} 
nyata, yang langgeng atau yang tidak pernah rusak" "61

Penjelasan tersebut selaras dengan Tafsir Al-Qur'an Suci Basa Jawi yang menjelaskan pentingnya pengetahuan batin seperti dimiliki Nabi Khidir di atas. Karenanya, ajaran sufi diyakini merupakan tahapan terpenting bagi seorang Muslim untuk mensucikan dan melembutkan jiwanya. Allah sendiri Maha Suci, maka dengan mengikuti laku sufi seseorang bisa mensucikan jiwa dan raganya untuk mencapai sifat manusia sejati sebagaimana Nabi Khidir. Sementara ketika manusia telah menjadi lembut jiwanya, ia akan berbelas kasih kepada sesamanya. Kiai Adnan menyebutnya sebagai kewajiban manusia yang paling utama terhadap sesama makhluq adalah saling berbelas kasih di antara mereka. ${ }^{62}$

Pandangan keselarasan dimensi batin dalam Islam dan budaya Jawa didasarkan pula pada kedekatan makna budaya dan akal. Dalam karyanya yang lain, Kiai Adnan misalnya, menjelaskan bahwa budaya berasal dari bahasa Sansakerta, budhi, berarti terang atau fajar atau sesuatu yang menerangi hati manusia. Padanan bahasa Arabnya adalah ' $a q l$ (mufrad) atau 'uqul (jamak). Selanjutnya dikatakan bahwa akibat dari adanya penerangan tersebut manusia bisa menyalurkan berbagai gagasan, gubahan, karangan, serta karya-karya lainnya. Adanya akal dan budi dalam diri manusia, karena mereka sejak awal dibekali oleh Tuhan berupa petunjuk akal (hidayah 'aqliyah). Akal dan budi yang mendasari munculnya kebudayaan menurutnya bisa dibagi menjadi tiga sesuai dengan proses perjalanannya: akal dan budi menuju kebenaran, menuju kesempurnaan, dan menuju keindahan. Kiai Adnan kemudian juga membagi kebudayaan menjadi dua bagian besar: kebudayaan lahir dan batin. Kebudayaan lahir meliputi alat atau bendabenda yang dibuat manusia untuk memenuhi kebutuhannya. Sedangkan kebudayaan batin

\footnotetext{
${ }^{61}$ Muhammad Adnan, Mutiara Hikmah, 133.

${ }^{62}$ Muhammad Adnan, Mutiara Hikmah, 9.
}

mencakup ilmu pengetahuan, adab, kesusilaan, termasuk di dalamnya filsafat dan tasawuf. $^{63}$

Dengan demikian, meski awalnya Islam dan Jawa merupakan dua entitas yang berbeda. Tetapi, dalam Tafsir Al-Qur'an Suci Basa Jawi keduanya kemudian dipertemukan melalui unsur keluhuran budi, kehalusan dan ajaran mistisisme yang ada pada Islam berupa sufisme dan budaya Jawa. Keduanya dipadukan hingga menghasilkan keselarasan ajaran yang disebut Islam Jawa. Perpaduan sufisme dan budaya Jawa ini misalnya, terlihat juga dalam bentuk bangunan keraton, ritual, upacara (sekaten, grebeg maulud, slametan dan lainnya), penanggalan dan lain-lain. Keraton-keraton di Yogyakarta dan Surakarta misalnya, jelas sengaja dirancang sebagai representasi jalan mistik sufi dan kosmos Islam. Keraton merupakan pusat kota, arsitektur dan ikonografinya yang sangat komplek, menyimbolkan ekplanasi-eksplanasi sufi mengenai siklus kehidupan, hubungan jalan mistik antara Allah dan manusia, dan antara keselahan normatif dan doktrin mistik. $^{64}$ Inilah yang menjadi inti akulturasi Islam Jawa.

\section{Islam Jawa sebagai Jalan Kebijaksanaan}

Bukan hanya melalui penggunaan bahasa Jawa halus dan sufisme Jawa, akulturasi Islam Jawa juga tidak lepas dari penyelarasan sebagai bagian dari jalan kebijaksanaan (alhikmah). Tafsir Al-Qur'an Suci Basa Jawi menjelaskan jalan hikmah ini ketika menafsirkan QS. Al-Nahl/16: 125:

(Muhammad) Sira ngajaka para manungsa marang agamane Pangeranira klawan kawicaksanaan lan piweling kang becik lan sira wangsulana wongkang ambantah ing sira klawan kang luwih becik. ${ }^{65}$

Artinya: (Muhammad) hendaklah engakau mengajak pada manusia kepada agama Tuhanmu dengan bijaksana dan pesan yang

\footnotetext{
${ }^{63}$ Muhammad Adnan, Mutiara Hikmah, 108-109.

${ }^{64}$ Mark R. Woodward, Islam Jawa, 122.

${ }^{65}$ R. Muhammad Adnan, Tafsir Al-Qur'an Suci,
} 477 . 
baik, dan hendaklah kamu memberikan balasan kepada orang yang menentangmu dengan balasan yang lebih baik.

Allah dalam ayat tersebut memerintahkan Nabi Muhammad agar mengajak manusia dengan jalan hikmah. Tafsir Al-Qur'an Suci Basa Jawi menyebutnya dengan kawicaksanaan. Dalam proses Islamisasi di Jawa, jalan kebijksanaan itu salah satunya ditempuh melalui jalur kebudayaan dan kesenian. Hal ini dilandasi oleh keyakinan bahwa Islam tidaklah anti pati terhadap kebudayaan yang ada di masyarakat, tetapi justru mengadopsinya dan menyelaraskannya dengan ajaran Islam. Keselarasan budaya masyarakat dengan Islam yang ditempuh melalui jalan hikmah itu dijelaskan pula oleh Kiai Adnan dalam karyanya yang lain sebagai ajaran damai dalam Islam dan tujuan utama Islam adalah menebar kedamaian di muka bumi.

Islam artinya damai, menurut Alquran surah Al-Anfal ayat 62 yang maksudnya: "Jikalau mereka itu suka damai, maka kamu harus menetapi cinta kepada damai pula dan percayalah ke hadirat Allah. Islam menganjurkan damai tidak hanya dalam teori, namun tiap-tiap salat lima waktu tentu penghabisannya memberi salam (damai dan menyalurkan hormat selamat) kepada sekalian umat yang ada di kiri-kanannya. ${ }^{66}$

Karena Islam adalah agama kedamaian, maka ia harus disebarkan dan didakwahkan secara damai pula. Pendekatan budaya merupakan salah satu hal terpenting dalam menyebarkan dan mendakwahkan Islam. Pendekatan ini pulalah yang dilakukan oleh para penyebar awal Islam di Jawa yang dianggap sebagai pahlawan kebudayaan sekaligus sebagai model ideal bagi Islam Jawa. ${ }^{67}$

Sunan Kalijaga misalnya, yang diyakini sebagai salah satu dari sembilan wali penyebar Islam atau walisongo, menyebarkan Islam di kalangan masyarakat Jawa yang beragama Hindu dan Buddha melalui pendekatan budaya. Ia berusaha memperkenalkan Islam tanpa melalui jalan konfrontasi langsung terhadap ajaran agama lama. Ia menyebarkan Islam melalui wayang kulit, dan bentukbentuk ekspresi budaya yang lain. Sunan Kalijaga pula yang diyakini menciptakan berbagai tradisi selametan dan upacara-upaca lainnya yang terus bertahan di kalangan Muslim Jawa hingga kini. ${ }^{68}$

Bagi keumuman Islam Jawa, Islam dan budaya setempat harus disinergikan dan diharmonisasikan, karena menurutnya ekspresi-ekspresi budaya yang sudah ada tidaklah bertentangan dengan ajaran Islam. Karenanya, ketika menyebarkan Islam seorang pendakwah haruslah tahu dan bisa memahami kondisi dan budaya masyarakat setempat. Dalam karyanya yang lain, Kiai Adnan menyatakan: "Barang siapa memberi pelajaran tidak selaras dengan yang yang mendengarkan, seperti menyebar benih di batu yang keras dan tidak dapat tumbuh". Ungkapan tersebut menurutnya didasarkan pada hadis Nabi: khatibu al-nas 'ala qadri 'uqulihim, anzalu al-nas manazilahum (Bicaralah kepada manusia menurut kekuatan akal pikirannya. Dan tempatkanlah manusia di tempatnya yang tepat). ${ }^{69}$

\section{SIMPULAN}

Berdasarkan kajian di atas dapat ditarik kesimpulan bahwa Tafsir Al-Qur'an Suci Basa Jawi berupaya melakukan harmonisasi antara ajaran yang bersumber dari Alquran dengan budaya Jawa. Sebuah karya yang gagasannya berasal dari Tafsir Anom V, lalu ditulis, disusun, dikumpulkan dan dipublikasikan oleh K.H. Raden Muhammad Adnan (1889-1969) dan anak-anaknya yang berada di lingkungan Keraton Surakarta. Hasil kajian ini menunjukkan bahwa Tafsir Al-Qur'an Suci Basa Jawi merupakan salah satu karya yang memperkuat keselarasan Islam dan budaya Jawa. Akulturasi Islam Jawa tampak pada penggunaan bahasa Jawa halus atau hormat, mistisisme Islam Jawa berupa keselarasan lahir-batin dan keharmonisan Islam Jawa sebagai jalan kebijaksanaan. Penggunaan

\footnotetext{
${ }^{66}$ Muhammad Adnan, Mutiara Hikmah, 85

${ }^{67}$ Mark Woodward, Islam Jawa, 146.
} 
bahasa Jawa halus misalnya, menunjukkan filosofi Jawa yang mengedepankan keluhuran budi dan kehalusan dalam berbahasa. Begitu juga dari aspek sufisme dalam tafsir ini juga menunjukkan keselarasan dengan budaya dan falsafah Jawa. Ia sejatinya bukanlah sesuatu yang bertentangan dengan ajaran Islam tetapi justru merupakan bagian puncak dari tahapan beragama Islam. Inilah salah satu kekhasan tafsir lokal di Nusantara yang mencerminkan dialog antara ajaran Islam dengan keragaman budaya Nusantara.

\section{DAFTAR PUSTAKA}

Adnan, Abdul Basit. Sejarah Masjid Agung dan Gamelan Sekaten di Surakarta. Surakarta: Yayasan Mardikintoko, t.th.

Adnan, Abdul Basit, dan Abdul Hayi Adnan. "Prof. K.H.R Muhammad Adnan dan pemikirannya dalam Islam." dalam Lima Tokoh Pengembangan IAIN Sunan Kalijaga Yogyakarta, diedit oleh Moh. Damami. Yogyakarta: Pusat Penelitian IAIN Sunan Kalijaga, 1998.

Adnan, Abdul Latif. Silsilah Keluarga Kanjeng Raden Pengulu Tafsir Anom V. Jakarta: t.p., 2008.

Adnan, Hakim. Masjid Tegal Sari Sala Genap 65 Tahun. Solo: Asya Grafika, 1999.

Adnan, Muhammad. Mutiara Hikmah. Solo: Perkumpulan Mardikintoko, 1996.

Adnan, R. Muhammad. Tafsir Al-Qur'an Suci Basa Jawi. Bandung: Al-Ma'arif, t.th.

Al-Dhahabi, Muhammad Husain. Tafsîr wa alMufassirûn. Vol. Juz I. Kairo: t.p., 1979.

Al-Qattan, Manna' Khalil '. Mabahis fi "Ulum Al-Qur"an. Beirut: Mansyurat al-Asr alHadis, n.d.

Al-Shabuni, Muhammad 'Ali. al-Tibyan fi Ulûm al-Qur'an. Jakarta: Dar al-Kutub alIslamiyah, 2003.

Baidowi, Ahmad. "Aspek Lokalitas Tafsir AlIklīl F̄̄ Ma'ānī Al-Tanz̄̄l Karya KH Mishbah Musthafa." Nun 1, no. 1 (2015): 33-62.

Burhanuddin, Mamat S. Hermeneutika ala Pesantren. Yogyakarta: UII Pres Yogyakarta, 2006.

Darmawan, Dadang. "Ortodoksi Tafsir:
Respons Ulama terhadap Tafsir Tamsjijjatoel-Moeslimien Karya K.H. Ahmad Sanusi." Sekolah Pascasarjana UIN Syarif Hidayatullah Jakarta, 2009.

Dhofier, Zamakhsyari. Tradisi Pesantren Studi Tentang Pandangan Hidup Kyai. Jakarta: LP3ES, 1994.

Federspiel, Howard M. "An Introduction to Qur'anic Commentaries in Contemporary Southeast Asia." The Muslim World 81, no. 2 (1991): 149-61. https://doi.org/10.1111/j.14781913.1991.tb03519.x.

- Popular Indonesian Literature of the Qur'an. Ithaca, New York: Cornel Modern Indonesia Project, 1994.

Gadamer, Hans-Georg. Truth and Method. London \& New York: Continuum, 2004.

Gilliot, Claude. "Exegesis of the Qur'ān: Classical and Medieval." In Encyclopaedia of the Qur'ān, diedit oleh Jane Dammen McAuliffe, 99-124. Qur'ānic Studies Online. Leiden-Boston-Koln: Brill, 2001.

Gusmian, Islah. "K.H. Raden Muhammad Adnan (1889-1969 M): Ulama dan Pejuang di Bidang Pendidikan, Politik, dan Agama dari Kauman Surakarta." Jurnal Lektur Keagamaan 15, no. 1 (2018): 207-32. https://doi.org/10.31291/jlk.v15i1.521.

-. "Tafsir Al-Qur'an Bahasa Jawa: Peneguhan Identitas, Ideologi dan Politik Perlawanan." Suhuf 9, no. 1 (November 2016): 141-68. https://doi.org/10.22548/shf.v9i1.116.

—. "Tafsir Al-Qur'an di Indonesia: Sejarah dan Dinamika." Nun 1, no. 1 (2015): 1-32.

Hisyam, Muhamad. Caught between Three Fires: The Javanese Pangulu under The Dutch Colonial Administration 1882-1942. Jakarta: INIS, 2001.

Ismail, Ibnu Qoyim. Kiai Penghulu Jawa, Peranannya pada Masa Kolonial. Jakarta: Gema Insani Press, 1997.

Junaidi, Akhmad Arif. "Penafsiran Al-Qur'an Penghulu Kraton Surakarta: Interteks dan Ortodoksi." Pascasarjana IAIN Walisongo, 2012.

Koentjaraningrat. Manusia dan Kebudayaan di Indonesia. Jakarta: Djambatan, 2004. 
Pengantar Ilmu Antropologi. Jakarta: Rineka Cipta, 2009.

Kontjaraningrat. Pengantar Antropologi 1. Jakarta: Rineka Cipta, 2003.

Lubis, Ismail. Falsifikasi Terjemahan AlQur'an. Yogyakarta: Tiara Wacana, 2001.

Maslukhin, M. "Kosmologi Budaya Jawa dalam Tafsîr al-Ibrîz Karya KH. Bisri Musthofa." Mutawatir 5, no. 1 (2015): 74 94. https://doi.org/10.15642/mutawatir.2015.5.1.74-94.

Muchoyyar HS, M. "KH. Muhammad Shalih Al-Samarani: Studi Tafsir Faid Al-Rahman fi Tarjamah Tafsir Kalam Malik AlDayyan." UIN Sunan Kalijaga Yogyakarta, 2000.

Muchtarom, Zaini. Islam di Jawa dalam Perspektif Santri dan Abangan. Jakarta: Salemba Diniyah, 2002.

Muhsin, Imam. Penafsiran Al-Qur'an dan Budaya Lokal: Studi Nilai-nilai Budaya Jawa dalam Tafsir al-Huda Karya Bakri Syahid. Jakarta: Badan Litbang dan Diklat Kementerian Agama RI, 2010.

Munir, Ghazali. Warisan Intelektual Islam Jawa. Semarang: Wali Songo Press, 2008.

Nasution. Sejarah Pendidikan Indonesia. Jakarta: Bumi Aksara, 1995.

Noer, Deliar. Gerakan Modern Islam di Indonesia, 1900-1942. Jakarta: LP3ES, 1980.

Pusponegoro, Ma'mun. Kauman: Religi, Seni, dan Tradisi. Surakarta: Paguyuban Kampung Wisata Batik, 2007.

Rida, Al-Sayyid Muhammad Rashid. Tafsir al-Qur'an al-Hakim al-Mashhur bi'ism Tafsir al-Mana. Vol. Juz 1. Kairo: Munsha Al-Manar, 1947.

Rohkmad, Abu. "Telaah Karakteristik Tafsir Arab-Pegon Al-Ibriz." Analisa 18, no. 1 (2011): $27-38$ https://doi.org/10.18784/analisa.v18i1.122.

Rohmana, Jajang A. "Memahami Al-Qur'an dengan Kearifan Lokal: Nuansa Budaya Sunda dalam Tafsir Al-Qur'an Berbahasa Sunda." Journal of Qur'an and Hadith Studies 3, no. 1 (2014): 79-99.

Setyowati, Norma, dan Danur Hadi Prasojo. Ritual Dalam Proses Pembangunan Masjid,
Studi Kasus Pembangunan Masjid Tegalsari Surakarta. Surakarta: t.p., 2008.

Siswayanti, Novita. "Javanese Ethical Values in Tafsir Al-Huda." Analisa 20, no. 2 (2013): 207-20. https://doi.org/10.18784/analisa.v20i2.177.

Supriyanto, Supriyanto. “Al-Qur'an Dalam Ruang Keagamaan Islam Jawa: Respon Pemikiran Keagamaan Misbah Mustafa dalam Tafsir al-Iklīl fī Ma'āni al-Tanzīl." Jurnal Theologia 28, no. 1 (2017): 29-54. https://doi.org/10.21580/teo.2017.28.1.129 4.

Ushama, Thamem. Methodology of Qur'anic Exegesis. Kuala Lumpur: A. S. Noordeen, 1995.

Wahidi, Ridhoul. "Hierarchical Language in the Interpretation of Al-Ibrīz li Ma'rifah Tafsīr Al-Qur'ān Al-'Āzīz by K.H. Bisri Musthofa." Suhuf 8, no. 1 (2015): 141-60.

Wielandt, Rotraud. "Exegesis of the Qur'an: Early Modern and Contemporary." In Encyclopaedia of the Qur'an, diedit oleh Jane Dammen McAuliffe, 124-42. LeidenBoston-Koln: Brill, 2001.

Woodward, Mark. Islam Jawa: Kesalehan Normatif versus Kebatinan. Diterjemahkan oleh Hairus Salim "Islam in Java: Normative Piety and Mysticism". Yogyakarta: LKiS, 1999. 